\title{
Long-term dietary exposure to lead in young European children: comparing a pan-European approach with a national exposure assessment
}

\author{
P.E. Boon ${ }^{\mathrm{a} *}$, J.D. Te Biesebeek ${ }^{\mathrm{a}}$, I. Sioen ${ }^{\mathrm{b}}$, I. Huybrechts ${ }^{\mathrm{b}}$, J. Moschandreas ${ }^{\mathrm{c}}, \mathrm{J}_{\text {. Ruprich }}^{\mathrm{d}}$, A. Turrini ${ }^{\mathrm{e}}$, \\ M. Azpirif ${ }^{\mathrm{f}}$ L. Busk ${ }^{\mathrm{g}}$, T. Christensen ${ }^{\mathrm{h}}$, M. Kersting ${ }^{\mathrm{i}}$, L. Lafay ${ }^{\mathrm{j}}$, K.-H. Liukkonen ${ }^{\mathrm{k}}$, S. Papoutsou ${ }^{1}$, \\ L. Serra-Majem ${ }^{\mathrm{m}}$, I. Traczyk ${ }^{\mathrm{n}}$, S. De Henauw ${ }^{\mathrm{b}}$ and J.D. Van Klaveren ${ }^{\mathrm{a}}$ \\ ${ }^{a}$ National Institute for Public Health and the Environment (RIVM), PO Box 1, NL-3720 BA Bilthoven, the Netherlands; \\ ${ }^{b}$ Department of Public Health, Ghent University, Ghent, Belgium; ' ${ }^{c}$ Department of Social Medicine, Faculty of Medicine, \\ University of Crete, Crete, Greece; ${ }^{d}$ National Institute of Public Health, Brno, Czech Republic; ${ }^{e}$ National Institute for Research \\ on Food and Nutrition (INRAN), Rome, Italy; ${ }^{f}$ Public Health Division of Gipuzkoa, BIODonostia Research Institute, \\ Department of Health of the Regional Government of the Basque Country, San Sebastian, Spain; ${ }^{g}$ National Food Administration \\ (NFA), Uppsala, Sweden; ${ }^{h}$ Department of Nutrition, National Food Institute, Technical University of Denmark (DTU), Kgs \\ Lyngby, Denmark; ${ }^{i}$ Research Institute of Child Nutrition, Rheinische Friedrich-Wilhelms-Universitaet Bonn, Bonn, Germany; \\ ${ }^{j}$ French Agency for Food, Environmental and Occupational Health and Safety (ANSES), Maisons-Alfort, France; ${ }^{k}$ Risk \\ Assessment Unit, Finnish Food Safety Authority (EVIRA), Helsinki, Finland; 'Research and Education Institute of Child \\ Health, Strovolos, Cyprus; ${ }^{m}$ Nutrition Research Foundation, Science Park of the University of Barcelona, Barcelona, Spain; \\ ${ }^{n}$ National Food and Nutrition Institute, Warsaw, Poland
}

(Received 6 April 2012; final version received 3 July 2012)

Long-term dietary exposures to lead in young children were calculated by combining food consumption data of 11 European countries categorised using harmonised broad food categories with occurrence data on lead from different Member States (pan-European approach). The results of the assessment in children living in the Netherlands were compared with a long-term lead intake assessment in the same group using Dutch lead concentration data and linking the consumption and concentration data at the highest possible level of detail. Exposures obtained with the pan-European approach were higher than the national exposure calculations. For both assessments cereals contributed most to the exposure. The lower dietary exposure in the national study was due to the use of lower lead concentrations and a more optimal linkage of food consumption and concentration data. When a pan-European approach, using a harmonised food categorisation system and "European" concentration data, results in a possible health risk related to the intake of an environmental chemical for a certain country, it is advisable to refine this assessment, as part of a tiered approach, using national occurrence data, including an optimised linkage between foods analysed and consumed for that country. In the case of lack of occurrence data, these data can be supplemented with data from the "European" concentration database or by generating additional concentration data at country level.

Keywords: long-term exposure assessment; lead; food; children; EXPOCHI; Europe

\section{Introduction}

In a project financed by the European Food Safety Authority (EFSA), with acronym EXPOCHI (EXPOsure in CHIldren) and described in detail by Huybrechts et al. (2011), the long-term dietary exposure to several food contaminants (lead, chromium and selenium) was calculated using national and regional food consumption data of (young) children (1-14 years) from 12 European countries in combination with occurrence data obtained from European Union Member States. Also the intake of 60 food colours was estimated. The exposure results have been published on EFSA's website (Boon, Sioen, et al. 2010;
Boon, te Biesebeek, et al. 2010; Huybrechts et al. 2010; Sioen et al. 2010), and have been partly incorporated in EFSA Opinions (EFSA 2010a, 2010b). This project met the need within Europe for harmonised approaches for risk assessment. In this paper we will address in more detail the exposure calculations to lead.

Within EXPOCHI the long-term dietary exposure to lead was estimated by combining food consumption data of 12 European countries using food categories and a database containing occurrence data on lead obtained from different Member States ("European" occurrence database). For this, foods coded at the national/regional level were assigned to 42 food 
groups, so that the food consumption data for all countries were categorised in a uniform way. The details of this categorisation are described by De Neve et al. (2010). The same categorisation was performed for the analysed commodities. Subsequently, the data were combined to assess the long-term exposure using one usual intake model. By doing all this, the exposure to lead was estimated in a uniform way for all countries.

The approach taken in EXPOCHI to assess the exposure to lead is similar to that taken by EFSA in a recent assessment of the cadmium exposure in Europe (EFSA 2012), as well as in possible future contaminant exposure assessments performed by this authority. For the cadmium exposure assessment EFSA made use of the EFSA Comprehensive European Food Consumption Database (Comprehensive Database) (EFSA 2011c). This database contains information on national food consumption patterns of 32 different dietary surveys carried out in 22 different Member States in which the food consumption data have been categorised according a harmonised system: the FoodEx1 system (EFSA 2011a). This database also includes the data of EXPOCHI. To assess the long-term intake of cadmium in the European population, the national food consumption data of the Comprehensive Database were linked to European occurrence data obtained from 22 Member States, three European Economic Area or other countries and some food business operators. This resulted in long-term exposure estimates to cadmium per country. Such international assessments performed by EFSA may form the basis for possible risk reduction measures at European Union level for contaminants (e.g. decrease of maximum limits) when the exposure results do not exclude that a possible health risk may exist. When confronted with such an international risk assessment, Member States may need to address two questions: (1) how does the international risk relate to that at Member State level? and (2) if relevant, how can an appropriate risk management strategy be justified at Member State level? To answer these questions, a Member State may decide to perform a national risk assessment using national monitoring data to corroborate the signalled international risk and the possible risk mitigation measures. A good comparison between the input data used and an appropriate exposure assessment model are elementary for answering these questions.

This paper presents a summary of the calculations performed as part of EXPOCHI, and it will compare them with a national lead exposure assessment in young children living in the Netherlands using lead concentration data as analysed in the Netherlands. The challenges and possibilities of the EXPOCHI approach will be discussed, as well as its restrictions in relation to national intake levels. This paper focuses on the exposure calculations of lead. However, the issues addressed are very likely applicable to exposure calculations of other contaminants that are performed following the same approach as in EXPOCHI.

\section{Methods}

\section{Food consumption data}

In EXPOCHI children's food consumption data from 14 dietary surveys originating from 12 European countries, with an age range of 1-14 years, were included. These data were considered representative at either a national (Cyprus, Czech Republic, Denmark, Italy, France, Netherlands, Poland, Spain (enKid study), Sweden) or a regional (Belgium, Finland, Germany, Greece, Spain Basque) level. This paper presents and discusses the results for the age range of 1-10 years. The Cypriot study (11-14 years) was not included. For a summary of the food consumption data used, see Table 1. For more details, see Boon, Sioen, et al. (2010). All surveys covered all days of the week. Personal characteristics such as sex, age and body weight were also available. For further details on the EXPOCHI study design and methodology, see Huybrechts et al. (2011).

In the national lead exposure assessment, the food consumption data of young children living in the Netherlands from the Dutch National Food Consumption Survey - Young Children 2005/2006 (Ocké et al. 2008) were used. In this survey, food consumption was recorded on 2 non-consecutive days (separated by $8-13$ days) of 1279 children aged 2-6 years using an estimated pre-structured dietary record. Amounts consumed were estimated as accurately as possible: using photographs, in household measures or, if possible, in exact weight or volume ( $\mathrm{g}$ or $\mathrm{ml}$ ). Data entry of the dietary records was performed in a standardised way via the EPIC-soft program. These food consumption data of Dutch young children were also included in EXPOCHI (Table 1).

\section{Lead occurrence data}

In EXPOCHI, lead concentration data as supplied to EFSA as part of DATEX-2008-0002 call for concentration data on lead covering the period 2003-2008 were used. In total, more than 100,000 lead concentrations in various food commodities were submitted, predominantly derived from 14 European countries. Germany was the major contributor providing $44 \%$ of the data, followed by France $(15 \%)$, Czech Republic $(9.7 \%)$ and Romania $(9.6 \%)$. After the data cleaning steps, 94,126 sample results were found suitable for use in the exposure assessments. These sample results covered all kinds of commodities that may contain lead, including milk, vegetables, fruits, cereals, fish and meat. 
Table 1. Information on the food consumption data per country used to model long-term dietary exposure to lead within the EXPOCHI project as reported in this paper.

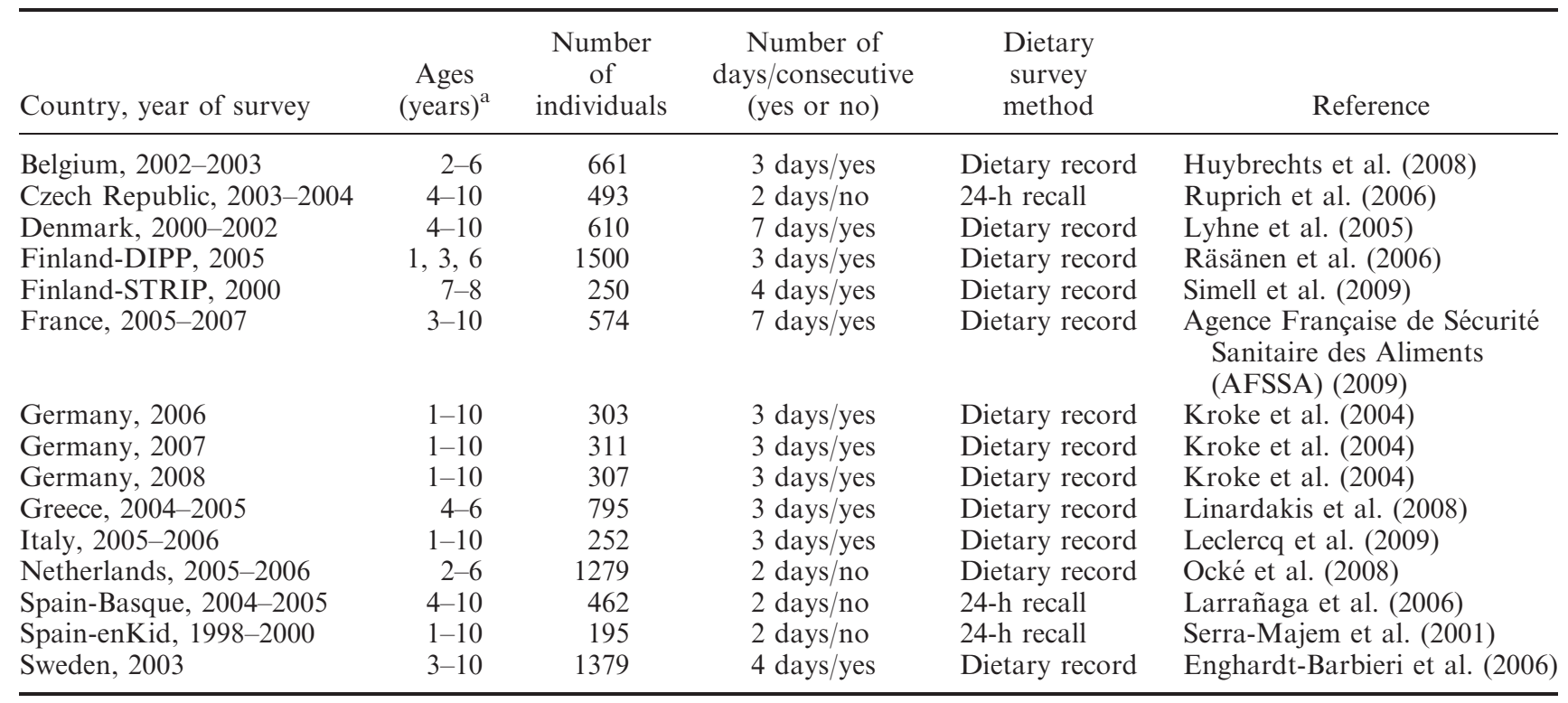

Note: ${ }^{a}$ Upper age of the range is included in the selection.

To calculate the exposure to lead using national lead concentrations, Dutch concentration data were used from Dutch monitoring programmes performed by the Netherlands Food and Consumer Product Safety Authority (NVWA 2002-2008), the Institute for Marine Resources \& Ecosystem Studies (2003 and 2007) and the Dutch Dairy Association (2005-2008). These data were stored in the Quality Agricultural Products database (http://www.chemkap.rivm.nl). Lead analyses were performed predominantly in raw agricultural commodities (RACs), including milk, vegetables, fruit, cereals, fish and meat, as well as liver and kidney. Since the lead concentrations in meat were limited, we derived meat concentrations from these two organ tissue concentrations, which are abundant. When lead enters an animal, including cattle, via their feed it is distributed throughout the body. When repeated exposure to background lead concentrations occurs, then the lead will distribute proportionally to all tissues. Based on the study of Vreman et al. (1986) the proportion of lead in meat:liver:kidney is 1:10:20. Using these proportions meat concentrations were derived from liver and kidney concentration data. In total 52 RACs were analysed with at least one sample containing lead at a concentration above the limit of detection (LOD) or quantification (LOQ). Lead concentrations in 45 RACs and 38 samples of infant food were reported to be below or at the LOD or LOQ.

It was observed that for wheat the Dutch occurrence database contained only analytical data from samples sampled in 2002 and that all reported concentrations were below a rather high LOQ of $200 \mu \mathrm{g} \mathrm{kg}^{-1}$, equalling the maximum level of lead in cereals (European Commission 2006). Since the food group cereals was one of the most important contributor to lead exposure in EXPOCHI (Boon, Sioen, et al. 2010), as well as in a recent EFSA Opinion on lead in food (EFSA 2010b), we substituted the national cereal concentrations for the mean lead concentrations of the food category "Cereal grain except rice" as reported in the EFSA Opinion. For rice, we used the mean concentrations as reported for the food category "Rice" in this Opinion (EFSA 2010b). To avoid possible further underestimation of the lead exposure, also the reported mean lead concentrations of the food category "Eggs" were included in the national lead occurrence database. Eggs were not sampled as part of the Dutch monitoring programme due to the absence of a maximum level for lead in this food group (European Commission 2006).

Concentrations of lead in drinking water were obtained from the Dutch National Drinking Water Database (http://www.os.amsterdam.nl/pdf/2010_ob_ cmilieu_3.pdf) and covered analyses performed in 2006-2008. This programme encompasses the results of measuring programmes of drinking water conducted by the Dutch drinking water companies, in compliance with drinking water regulations as enforced by the "Dutch Drinking Water Inspectorate." In total, 7667 drinking water samples were analysed in this period.

\section{Assignment concentration data to consumed foods}

To link the food consumption and lead concentration data within EXPOCHI, both the foods reported in the different children's food consumption databases and 
those present in the occurrence database were categorised in 42 food groups (see Table A1 in Appendix 1). The grouping of analysed foods in the 42 food groups was performed by EFSA. No information on lead concentrations of the individual products constituting the food groups was available within EXPOCHI. Further details of the categorisation procedure used for the foods is reported in the food consumption databases (e.g. De Neve et al. 2010).

The national lead analyses were performed predominantly in RACs. To link lead concentrations analysed in these commodities, including drinking water, to the foods recorded in the food consumption survey, the consumption of foods was translated into the consumption of RACs using the conversion model for primary agricultural products (van Dooren et al. 1995; Boon et al. 2009). In this way, the lead concentrations analysed in RACs (such as pork, milk, cereals etc.) could be linked directly to consumed foods and also composite foods were included in the exposure assessment. Concentrations analysed in infant food were linked directly to consumption levels of these foods.

\section{Concentration scenarios regarding lead concentrations assigned to non-detect samples}

When reporting contaminant concentrations analysed in monitoring programmes, actual numeric values of concentrations are only reported when the measurements exceed the LOD or LOQ. In the exposure assessments performed within EXPOCHI, these measurements (the so-called non-detect samples) were assigned either $0 \mu \mathrm{g} \mathrm{kg}^{-1}$ (lower bound, LB) or the limit value itself (upper bound, UB). See Table A1 in Appendix 1 for the resulting mean lead concentrations per food group for both concentration scenarios. The same approach was taken in the Dutch national exposure assessment. However, for this assessment also a medium bound (MB) concentration scenario was applied in which all non-detect samples of commodities (including drinking water) with at least one sample with a concentration at or above the LOD or LOQ were assigned a concentration equal to half the limit value. The remaining non-detect samples were assumed to contain no lead. This scenario was chosen as a more optimal approach to link the analysed concentrations to the foods consumed as opposed to assigning all non-detect samples a concentration equal to $0 \mu \mathrm{g} \mathrm{kg}^{-1}$ or the relevant limit value. The resulting national lead concentrations per concentration scenario are listed in Table B1 in Appendix 2. Since in the EFSA Opinion on lead in food no MB concentrations are reported, we used for the $\mathrm{MB}$ concentration scenario the mean UB concentrations for cereals, rice and eggs.
Mean lead concentrations were used to estimate the exposure, since lead is known to be toxic after a longer period of ingestion (EFSA 2010b).

\section{Modelling of the long-term exposure}

In both studies, the long-term dietary exposure to lead was estimated using the betabinomial-normal (BBN) model, as implemented in the Monte Carlo Risk Assessment program (MCRA), version 6.2 (de Boer and van der Voet 2007). The BBN approach models separately the contaminant intake frequency and positive intake amounts as a function of age to produce the long-term exposure distribution. For this, the positive amounts distribution is logarithmically transformed into a normal distribution to remove the within-person variation that is of no interest for this type of exposure (Hoffmann et al. 2002; de Boer et al. 2009). After removal of the within-person variation, the logarithmically transformed positive exposure distribution is back-transformed and combined with the intake frequency to estimate the long-term exposure distribution. This is achieved by sampling a large number of times from both the exposure frequency and the back-transformed positive exposure distribution (Monte Carlo integration). The long-term exposure estimates are adjusted for the individual's body weight.

The uncertainty in the exposure analyses due to the limited size of the concentration and food consumption dataset was quantified in the national Dutch exposure calculation using the bootstrap approach. For more details, see Boon et al. (2011). The uncertainty analyses resulted in a $95 \%$ confidence interval around the different percentiles of exposure.

\section{Results}

Table 2 lists the estimated percentiles of long-term dietary lead exposure of children for the LB and UB concentration scenarios as applied in EXPOCHI. The percentiles listed represent the lowest and highest exposure level as a function of age per country. Note that the age ranges differ per country (Table 2). The exposure to lead was highest in the youngest children. The P95 of exposure of the LB concentration scenario ranged from $1.0 \mu \mathrm{glead} \mathrm{\textrm {kg } ^ { - 1 } \text { bw day }}{ }^{-1}$ in Swedish and Spanish kids aged 10 years to $3.1 \mu \mathrm{g}$ lead $\mathrm{kg}^{-1}$ bw day ${ }^{-1}$ in 1-year-old children from Finland. The lowest P95 of exposure, $1.9 \mu \mathrm{g}$ lead kg ${ }^{-1}$ bw day ${ }^{-1}$, in the UB concentration scenario was calculated for Spanish-Basque children aged 10 years. Finnish children aged 1 year had, as in the LB concentration scenario, the highest P95 of exposure in the UB concentration scenario, i.e. $5.5 \mu \mathrm{g}$ lead $\mathrm{kg}^{-1}$ bw day ${ }^{-1}$. Overall, it is interesting to observe that several percentile intervals did not overlap 
Table 2. Ranges of percentiles of dietary lead exposure estimates as a function of age $\left(\mu \mathrm{kg}^{-1} \mathrm{bw} \mathrm{day}^{-1}\right)$ of children $(1-10 \mathrm{years})$ living in 11 different European countries, following two scenarios of assigning lead concentrations to non-detect samples.

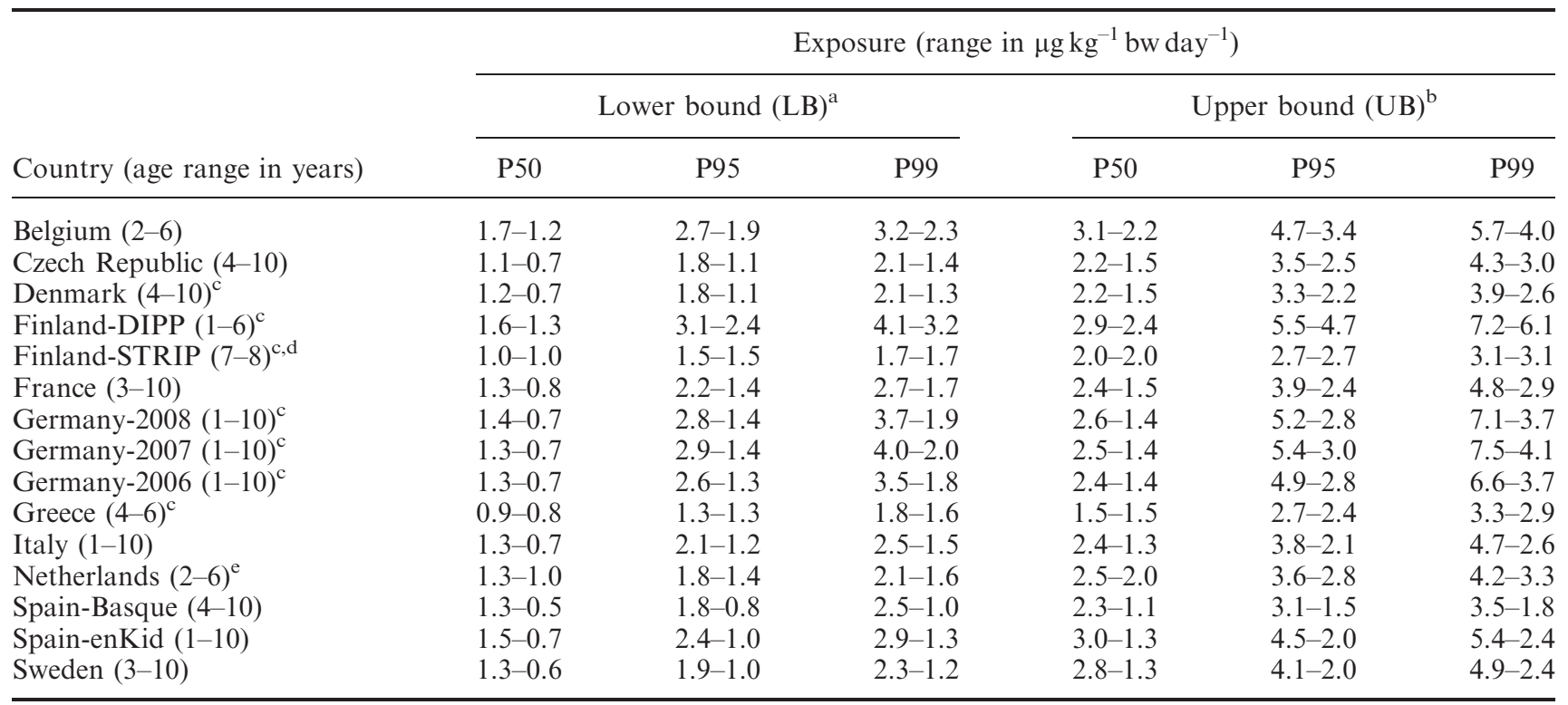

Notes: ${ }^{\mathrm{a}} \mathrm{LB}=$ non-detect samples were assigned a concentration of $0 \mu \mathrm{g} \mathrm{kg}^{-1}$.

${ }^{\mathrm{b}} \mathrm{UB}=$ non-detect samples were assigned a concentration equal to the limit of detection (LOD) or quantification (LOQ).

${ }^{c}$ Positive daily exposure distributions for both the LB and UB concentration scenario could not be transformed satisfactorily to normality using a logarithmic transformation. Exposures may therefore not be correct.

${ }^{\mathrm{d}}$ Lead exposure was independent of age at $p=0.05$.

${ }^{\text {e}}$ Positive daily exposure distribution for the LB concentration scenario could not be transformed satisfactorily to normality using a logarithmic transformation. Exposures may therefore not be correct.

in both concentration scenarios (e.g. P50 of Belgium, Czech Republic, Denmark and France), whereas others did (e.g. P50 Belgium and Finland-DIPP) (Figure 1). The same was true for the P95 and P99 of exposures. Because a common concentration dataset was used, these similarities and differences in exposure were due to cross-country differences in food habits. For a more detailed description of the exposure results, see Boon, Sioen, et al. (2010).

In the EXPOCHI LB concentration scenario, food groups that contributed most to the exposure were "cereals," "vegetables," "miscellaneous" and "fruit (juices)." In the UB concentration scenario, also the food groups "cereals," "vegetables" and "miscellaneous" contributed most to the exposure. However, the food group "fruit juices" was replaced by the food groups "soft drinks/edible ices." As an example, Table 3 lists the top three food groups contributing most to the long-term lead exposure distribution of children living in France, Italy, the Netherlands and Spain, including the percentage of contribution. Note that the age range was 2-6 years for the Dutch children, whereas for France the range was 3-10 years and for Italy and Spain 1-10 years.

Table 4 lists the national percentiles of long-term exposure to lead as a function of age in young Dutch children for the three concentration scenarios. The exposures decreased with age and were lowest in the
LB and highest in the UB concentration scenario, as expected (Table 4). In the LB concentration scenario the P95 of exposure ranged from $0.33 \mu \mathrm{g} \mathrm{kg}^{-1}$ bw day ${ }^{-1}$ in 6-year-olds to $0.46 \mu \mathrm{g} \mathrm{kg}^{-1}$ bw day ${ }^{-1}$ in 2-year-olds. Corresponding numbers for the $\mathrm{MB}$ concentration scenario were 0.73 and $1.0 \mu \mathrm{g} \mathrm{kg}^{-1}$ bw day ${ }^{-1}$ and for the UB scenario 1.2 and $1.8 \mu \mathrm{g} \mathrm{kg}^{-1}$ bw day ${ }^{-1}$, respectively (Table 4).

Figure 2 plots the most important sources of exposure for the three concentration scenarios over all ages (2-6 years). For the LB concentration scenario cereals $(56 \%)$ contributed most to the long-term exposure to lead, followed by the food groups drinking water $(12 \%)$, fruit $(11 \%)$ and vegetables $(10 \%)$. In the MB concentration scenario the food group cereals contributed also most to the exposure $(35 \%)$, followed by milk $(19 \%)$ and fruit $(16 \%)$. In the UB concentration scenario, the same food groups contributed most to the exposure as in the MB concentration scenario: $21 \%$ for cereals, $22 \%$ for milk and $23 \%$ for fruit.

\section{Discussion}

In Europe there is a need for harmonised approaches for risk assessment, as well as harmonised procedures to collect accurate input data in order to ensure their quality and that exposures calculated for different 


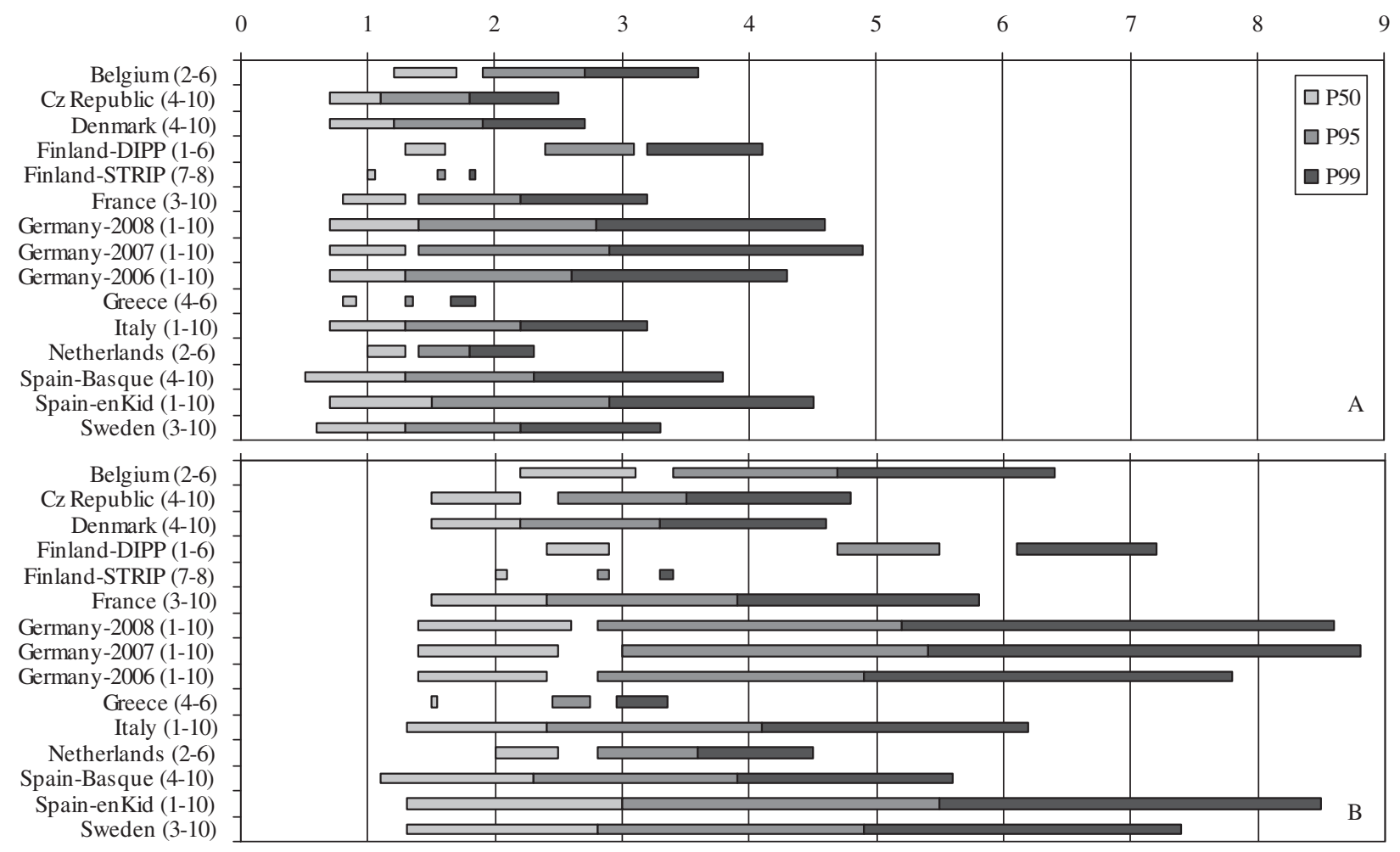

Figure 1. Ranges of percentiles of dietary lead exposure estimates as a function of age $\left(\mu \mathrm{g} \mathrm{kg}^{-1} \mathrm{bw} \mathrm{day}^{-1}\right)$ of children $(1-10$ years) living in 11 different European countries, following two scenarios of assigning lead concentrations to non-detect samples: lower bound (A) and upper bound (B).

Table 3. Contribution ( $\%$ ) of the top three food groups ${ }^{\mathrm{a}}$ contributing most to the dietary exposure to lead of children, aged $1-10$ years (for the Netherlands 2-6 years), living in Germany (2007), Italy, the Netherlands and Spain, following two scenarios of assigning lead concentrations to non-detect samples.

\begin{tabular}{|c|c|c|c|}
\hline Country & 1 & 2 & 3 \\
\hline \multicolumn{4}{|c|}{ Lower bound $(L B)^{\mathrm{b}}$} \\
\hline France & Miscellaneous 24\% & Cereals 19\% & Vegetables 17\% \\
\hline Netherlands ${ }^{\mathrm{d}}$ & Miscellaneous 19\% & Cereals $18 \%$ & Vegetables $14 \%$ \\
\hline Spain-enKid & Vegetables 19\% & Miscellaneous 17\% & Cereals $17 \%$ \\
\hline Italy & Cereals $24 \%$ & Vegetables $18 \%$ & Fruit $8 \%$ \\
\hline Netherlands & Soft drink/edible ices $17 \%$ & Cereals $15 \%$ & Miscellaneous $11 \%$ \\
\hline Spain-enKid & Cereals $15 \%$ & Vegetables $14 \%$ & Miscellaneous $10 \%$ \\
\hline
\end{tabular}

Notes: ${ }^{a}$ For a more elaborate description of (some of) the food groups, see Huybrechts et al. (2011).

${ }^{\mathrm{b}} \mathrm{LB}=$ non-detect samples were assigned a concentration of $0 \mu \mathrm{g} \mathrm{kg}^{-1}$.

${ }^{\mathrm{c}} \mathrm{UB}=$ non-detect samples were assigned a concentration equal to limit of detection (LOD) and quantification (LOQ).

${ }^{\mathrm{d}}$ Positive daily exposure distribution for the LB concentration scenario could not be transformed satisfactorily to normality using a logarithmic transformation. Exposures may therefore not be correct.

countries within Europe are comparable. There are continuous efforts within Europe to harmonise the collection of food consumption data as, for example, within the European Union projects EFCOSUM (Brussaard et al. 2002) and EFCOVAL (de Boer et al. 2011), and the preparations of EFSA to arrive at a pan-European dietary survey (EFSA 2009), pilot studies among children (PANCAKE) and adults (PILOT-PANEU). These efforts have until now not yet resulted in the collection of food consumption data 

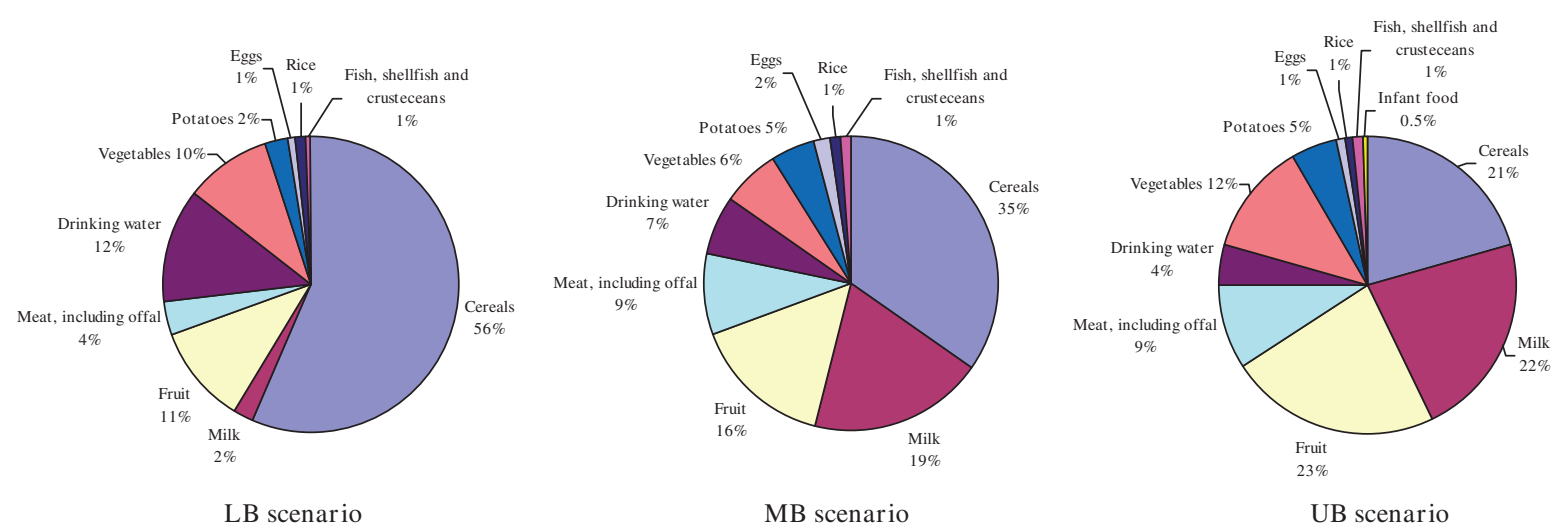

Figure 2. (Colour online). Contribution (\%) of various food groups to the total dietary lead exposure of Dutch children (2-6 years) calculated in the national Dutch exposure calculation. Samples with concentrations below the limit of detection (LOD) or quantification (LOQ) were assigned a concentration according to three scenarios: zero concentration (LB concentration scenario), only $0.5 \mathrm{LOQ}$ or $0.5 \mathrm{LOD}$ for foods, including drinking water, with at least one sample with a concentration at or above the LOQ or LOD (MB concentration scenario) and concentration equal to the LOD or the LOQ (UB concentration scenario).

at a pan-European level. Until that time, food consumption data collected at a national/regional level are used to assess the exposure within Europe, acknowledging methodological differences, mainly related to the dietary assessment methods used, number of days included, and the study subjects sampling criteria.

In EXPOCHI national/regional food consumption data on children were used to assess the exposure to different chemicals, including lead. Despite the differences in methodologies used to collect these data, in this project an effort was made to make the exposure assessments performed with these data as comparable as possible. This was achieved by the use of (1) a common food classification system, (2) the same lead concentration data ("collected European data") as input for all participating countries, and (3) a harmonised approach to assess the long-term dietary exposure to lead. This paper reported on the dietary exposure to lead for the Netherlands using national concentration data. Comparing these exposure results with the EXPOCHI exposure results for the Netherlands shows that the EXPOCHI exposures were higher for the LB and UB concentration scenarios. For example, the P95 of the LB concentration scenario ranged from 1.4 to $1.8 \mu \mathrm{g}$ lead $\mathrm{kg}^{-1}$ bw day ${ }^{-1}$ in EXPOCHI compared with 0.33 to $0.46 \mu \mathrm{g}$ lead kg ${ }^{1} \mathrm{bw} \mathrm{day}^{-1}$ in the national exposure assessment. Overall, the EXPOCHI exposure results for the Netherlands were on average $75 \%$ higher in the LB concentration scenario and $54 \%$ in the UB concentration scenario compared with the national exposure results. The LB concentration scenario in EXPOCHI for the Netherlands resulted also in higher exposures than the national MB concentration scenario (on average about $40 \%$ ), including the $97.5 \%$ upper confidence limit, whereas the results of the national UB concentration scenario were on average comparable with those of the EXPOCHI LB concentration scenario for the Netherlands. Explanations for these differences in exposure are differences in the linkage between foods consumed and analysed and the lead concentrations used in the analyses. These two differences between the two exposure studies will be discussed in more detail in the next two sections.

\section{Linkage between foods consumed and analysed}

In EXPOCHI a common food classification system was used to link the food consumption data as present in the national/regional food consumption surveys to the lead occurrence data. Such a common food classification system is an important aspect of the harmonisation of dietary exposure assessments. To link the food consumption data with the lead occurrence data received from EFSA, foods were categorised in 42 broad communal groups. During this process certain details on the foods entered in the different regional/national food consumption databases were inevitably lost, resulting in an imperfect link between the foods consumed and those analysed. Due to the use of broad food groups, it is very likely that the exposure was overestimated. This was even more likely given the fact that in cases of doubt, in EXPOCHI foods were categorised in the food group linked to the highest lead concentration to avoid possible underestimation of the exposure (De Neve et al. 2010).

For an optimal exposure result both the food consumption and occurrence data should preferably be categorised at the highest level of detail as possible. This approach was applied in the national exposure assessment in which we had information on the actual 
foods analysed as opposed to EXPOCHI. Furthermore, with the use of the conversion model in which all foods recorded in the food consumption survey were converted to their RAC ingredients (van Dooren et al. 1995; Boon et al. 2009), the lead concentrations analysed in raw commodities could be linked directly to consumption levels of these commodities. In this way, also composite foods were included in the assessment. Linking lead concentrations analysed in specific foods/ingredients to their specific consumption levels will in general result in a more accurate estimation of the exposure than when a food grouping approach of linkage is used. For national assessments, optimal linkages between foods consumed and analysed can be achieved if the data allow this. At the European level compromises will always be needed when selecting an approach that suits the data of all Member States. For example, when using input data collected via different methodologies, the poorest data available will often determine at which level harmonisation is possible, potentially affecting negatively the representativity of the ensuing exposure results at Member State level. For example, in the EFSA Opinion on cadmium, concentration and consumption data were mainly linked at the second level of the FoodEx1 system (EFSA 2012). This was the level at which all data providers were at least able to classify correctly the large majority of their food items (EFSA 2011a, 2011c). FoodEx1, however, contains in total five hierarchical food levels with potentially more accurate links between food consumption and concentration data for a large part of the countries.

\section{Lead concentration data}

In EXPOCHI an "European" lead concentration database was used to assess the lead exposure in the different countries. These data were supplied by EFSA that received them from the different Member States under Regulation (EC) No. 178/2002 (European Commission 2002). As in EXPOCHI, EFSA uses these data, combined with country-specific consumption data, to calculate the dietary exposure per country. No country-specific concentration data are used in these assessments (e.g. EFSA 2010b, 2010c, 2012). An important issue when evaluating countryspecific dietary exposures obtained with a "European" concentration database is the representativeness of the concentration data in relation to the concentrations to which consumers in different European countries are exposed. In EXPOCHI, the lead concentration data were predominantly supplied by 14 Member States, of which $44 \%$ was by Germany and $15 \%$ by France. The concentration data used in EXPOCHI did therefore not cover equally all European countries involved in the present study. Due to differences in food consumption patterns between countries and the diversity of foods on the market this representativeness is not necessarily met. A comparison between the Dutch concentrations used in the national assessment and those of the "European" lead concentration data showed that EXPOCHI concentrations were on average higher than those analysed in Dutch monitoring programmes (Table 5), resulting very likely in higher exposures in EXPOCHI. Especially lead concentrations in potatoes, fruit and vegetables (three frequently consumed food groups) were higher than those based on the national Dutch concentration data (Table 5). This approach of merging all the concentration data of different countries within Europe may be very helpful for countries that have no or only insufficient national concentration data available. In those cases, the use of a "European" database to replace or complement national data may be preferable above no or only limited data. A more advanced approach could be to link the data present in European concentration databases at country level if it is expected that concentrations may differ per country and the national data are of enough quality. Such an approach would also give the flexibility to select the data of those countries that most likely represent the situation in the country of interest.

Another important factor affecting the representativeness of the concentration data is sampling strategy, such as sampling randomly with the aim to analyse all relevant foods that may contain the contaminant of interest or with pre-knowledge of possible contamination by focusing only on a sub-selection of the highly contaminated foods. No information on the sampling method used was available within EXPOCHI, so that it cannot be excluded that the database may contain data from highly contaminated foods. For the national Dutch occurrence data, the foods (including drinking water) analysed by the majority of suppliers were sampled as part of monitoring programmes in which foods were sampled without prior knowledge of possible contamination, and can thus be viewed as representing lead concentrations that consumers may encounter when consuming these foods. This is however not always true for foods sampled by the NVWA. With help of the NVWA, we removed the samples taken by this authority as part of their targeted sampling programmes from the analyses. By this approach we feel that the majority of the data used in the national assessment can be viewed as being obtained from monitoring activities without prior knowledge of contamination.

Also the coverage of the foods is an important factor to address when evaluating exposure results. The occurrence data used by EXPOCHI covered, based on the 42 food groups, all relevant foods that may contain lead. For the Dutch occurrence data it was observed that for cereals only very limited data for 
Table 5. Mean lead concentrations $\left(\mu \mathrm{g} \mathrm{kg}^{-1}\right)$ per food group as used in EXPOCHI and in the national Dutch exposure calculation.

\begin{tabular}{|c|c|c|c|c|c|}
\hline \multirow{2}{*}{ Food group } & \multicolumn{5}{|c|}{ Mean lead concentration $\left(\mu \mathrm{g} \mathrm{kg}^{-1}\right)$} \\
\hline & \multicolumn{2}{|c|}{ EXPOCHI } & \multicolumn{3}{|c|}{ Dutch exposure calculation } \\
\hline Drinking water & 1.5 & 3 & 1.5 & 1.8 & 2.1 \\
\hline Milk & 5 & 11.7 & 0.27 & 5.1 & 10.1 \\
\hline Potatoes & 35.5 & 45.7 & 1.9 & 9.3 & 16.8 \\
\hline Vegetables & 35.5 & 45.7 & 18.2 & 26.7 & 33.7 \\
\hline Meat, including offal & 25.3 & 27.3 & 9.3 & 26.8 & 44.1 \\
\hline Fruit & 10.5 & 22.8 & 2.9 & 16.9 & 29.7 \\
\hline Fish & 14.6 & 46.9 & $2.1-110^{\mathrm{g}}$ & $27-157^{\mathrm{g}}$ & $53-204$ \\
\hline
\end{tabular}

Notes: ${ }^{\mathrm{a}} \mathrm{LB}=$ lower bound; non-detect samples were assigned a concentration of $0 \mu \mathrm{g} \mathrm{kg}^{-1}$.

${ }^{\mathrm{b}} \mathrm{UB}=$ upper bound; non-detect samples were assigned a concentration equal to limit of detection (LOD) or quantification (LOQ).

${ }^{\mathrm{c}}$ All non-detect samples of foods (including drinking water) with at least one sample with a concentration at or above the LOD or the LOQ were assigned a concentration equal to 0.5 LOD or $0.5 \mathrm{LOQ}$. The remaining non-detect samples were assigned $0 \mu \mathrm{g} \mathrm{kg}^{-1}$.

${ }^{\mathrm{d}}$ Cereals include wheat, rye, maize, millet, oat, buckwheat and barley.

${ }^{\mathrm{e}}$ Mean LB concentration as reported by European Food Safety Authority (EFSA) (2010b).

${ }^{\mathrm{f}}$ Mean UB concentrations as reported by EFSA (2010b).

${ }^{\mathrm{g}}$ Range of eel, herring, sardines, mackerel, tuna, salmon and trout.

wheat and rye were available, and that there were no data for eggs. For these commodities the concentration data as published by EFSA (2010b) were therefore used to avoid possible under-estimation of the exposure in young children. The analyses performed in drinking water and meat, including offal can be deemed to represent the Dutch situation, given the large amount of samples analysed over time, 7667 and 3536 , respectively, and the regularity in which analyses were performed over the years. However, concerning the analyses performed in the other food groups, this is less clear, given the high level of non-detect samples (e.g. milk $(98 \%))$, the diversity of individual foods included in a food group and the low number of analyses per food group (e.g. potatoes (19 samples), infant food (35 samples)). The lead concentration data used in EXPOCHI were obtained from different Member States and therefore more data were available, both more samples for a certain food group, as a better coverage of all food groups. Supplementation of national occurrence data with data of a "European" database could be helpful to improve food coverage, provided this can be justified based on environmental conditions at country level. In the case of the wheat concentrations used in the national Dutch assessment, this may be justifiable. The majority of the wheat present in wheat meal is imported from Germany (Statistics Netherlands; http://www.cbs.nl), the country that supplied most of the lead concentration data in the "European" database. Another approach to increase the coverage of foods is to perform additional chemical analyses at country level in those foods for which occurrence data are missing and no "European" alternative or country-specific data of another, comparable country are available. In case of financial constraints, these additional analyses could be focused on those missing foods that are expected to contribute significantly to the exposure.

\section{Use of a harmonised approach to assess the exposure}

Apart from the input data, also the model used to assess the long-term exposure determines the outcome of the exposure assessment. In both EXPOCHI and the national Dutch exposure calculation, the BBN model was used to assess the long-term exposure. With this model the long-term exposure is calculated by removal of the within-person variation. For this the positive daily exposure distribution was logarithmically transformed in a normal distribution, an important prerequisite to use the BBN model for estimating long-term exposure which should always be checked. For this we used the normal quantile-quantile $(\mathrm{q}-\mathrm{q})$ plot as proposed by de Boer et al. (2009). In those cases in which the transformed positive daily exposure distribution is markedly non-normal, the results may be misleading. 
For seven surveys in EXPOCHI, the BBN model could not be used in a satisfactory way due to this, namely those from Denmark, Finland (both studies), Germany (all three studies) and Greece, in both concentration scenarios, and the Netherlands in the LB concentration scenario. For these surveys and scenarios, the long-term exposure estimates may be wrong. As described in Boon, Sioen, et al. (2010) the reason for this was a strong contribution from one specific food group to the right tail of the logarithmically transformed positive exposure distribution, except for Germany and Finland for which no food groups could be identified. Removal of the relevant food group from the respective databases resulted in a satisfactory transformation of the positive daily exposure distribution into a normal distribution using a logarithmic transformation (Boon, Sioen, et al. 2010). Given this observation, the linkage of the food consumption data to the analysed foods using a rather rough food categorisation system of 42 food groups may have been the reason why some positive daily exposure distributions could not be transformed to normality satisfactorily using a logarithmic transformation. The BBN assumption of normality of the logarithmically transformed positive daily lead exposure was met in both concentration scenarios in the national Dutch exposure calculation.

When transformation to normality fails, a simpler approach can be used to assess the long-term exposure: the observed individual means (OIM; Boon et al. 2011). This is a simple method that averages the individual intake over survey days. In this approach the within-person variation is not corrected for, resulting in more conservative estimates of long-term exposure in the right tail of the exposure distribution compared to models that do so, like BBN. This approach is used by EFSA to assess the long-term exposure to environmental contaminants via food (EFSA 2011b). Applying the OIM approach to the EXPOCHI LB concentration scenario for the Netherlands resulted in a similar exposure at P50 $\left(1.1 \mu \mathrm{g}\right.$ lead $\mathrm{kg}^{-1}$ bw day $\left.{ }^{-1}\right)$, but in higher exposures at P95 and P99 compared with the BBN results (Table 2), 1.9 and $2.8 \mu \mathrm{glead} \mathrm{kg}^{-1}$ bw day ${ }^{-1}$, respectively. The OIM approach as implemented in MCRA version 6.2 does not allow to assess the exposure as a function of age.

\section{Conclusion}

With EXPOCHI a great step forward has been set in the harmonisation of risk assessment approaches within Europe. The EXPOCHI data have been incorporated in the EFSA Comprehensive Database using the FoodEx1 food classification system (EFSA 2011a, 2011c). With this Comprehensive Database, in combination with European concentration data and a simple approach to assess long-term exposure, European long-term exposure assessments are performed to contaminants (EFSA 2012). The national Dutch exposure study resulted in lower estimates of lead exposure compared with a "European" assessment using the same Dutch food consumption data due to the use of national lead concentration data linked to food consumption data at a higher level of detail. Given the way in which the EXPOCHI results were obtained (linkage via broad food groups and use of a "European" concentration database) we argued that an overestimation of the exposure may be expected. This approach can therefore be used as a first-tier assessment. When such an assessment results in a possible health risk related to the intake of a chemical for a certain country, it is advisable to refine this assessment by using national occurrence data, including a more optimised linkage between foods analysed and consumed for that country, and also, if not used in the first tier, an intake model that calculates the long-term exposure by removal of the within-person variation. Such an assessment should include an examination of the completeness of the national concentration data regarding coverage of potential food sources of exposure and of the underlying sampling strategy used to obtain the data. In case of lack of national occurrence data, these can be supplemented with concentration data from the European database provided this can be justified based on the environmental conditions at country level or by generating additional national concentration data using, in the case of financial constraints, a monitoring scheme focused on those missing foods that are expected to contribute significantly to the exposure.

\section{Acknowledgements}

This project was funded by the European Food Safety Authority (EFSA) (with a grant under the Call of proposals CFP/EFSA/DATEX/2008/01) and the Netherlands Food and Consumer Product Safety Authority (NVWA).

\section{References}

Agence Française de Sécurité Sanitaire des Aliments (AFSSA). 2009. Summary of the Report of the 2006/ 2007 Individual and National Study on Food Consumption 2 (INCA 2). Maison-Alfort (France): AFSSA. Available from: http://www.afssa.fr/Documents/ PASER-Sy-INCA2.pdf/

Boon PE, Bonthuis $\mathrm{M}$, van der Voet $\mathrm{H}$, van Klaveren JD. 2011. Comparison of different exposure assessment methods to estimate the long-term dietary exposure to dioxins and ochratoxin A. Food Chem Toxicol. 49:1979-1988. 
Boon PE, Ruprich J, Petersen A, Moussavian S, Debegnach F, van Klaveren JD. 2009. Harmonisation of food consumption data format for dietary exposure assessments of chemicals analysed in raw agricultural commodities. Food Chem Toxicol. 47:2883-2889.

Boon PE, Sioen I, van der Voet H, Huybrechts I, De Neve M, Amiano P, Azpiri M, Busk L, Christensen T, Hilbig A, et al. 2010. Long-term dietary exposure to lead in young children living in different European countries. Scientific Report submitted to EFSA. Available from: http://www.efsa.europa.eu/

Boon PE, te Biesebeek JD, Sioen I, Huybrechts I, De Neve M, Amiano P, Arganini C, Azpiri M, Busk L, Christensen T, et al. 2010. Long-term dietary exposure to chromium in young children living in different European countries. Scientific Report submitted to EFSA. Available from: http://www.efsa.europa.eu/

Brussaard JH, Löwik MRH, Steingrímsdóttir L, Møller A, Kearney J, De Henauw S, Becker W. 2002. A European food consumption survey method - conclusions and recommendations. Eur J Clin Nutr. 56(Suppl. 2):S89-S94.

de Boer EJ, Slimani N, van 't Veer P, Boeing H, Feinberg M, Leclercq C, Trolle E, Amiano P, Andersen LF, Freisling $\mathrm{H}$, et al. on behalf of the EFCOVAL Consortium. 2011. Rationale and methods of the European Food Consumption Validation (EFCOVAL) Project. Eur J Clin Nutr. 65:S1-S4.

de Boer WJ, van der Voet H. 2007. MCRA, Release 6. A web-based programme for Monte Carlo Risk Assessment. Bilthoven and Wageningen (the Netherlands): Biometris, Wageningen University and Research Centre and National Institute for Public Health and the Environment (RIVM). de Boer WJ, van der Voet H, Bokkers BGH, Bakker MI, Boon PE. 2009. Comparison of two models for the estimation of usual intake addressing zero consumptions and non-normality. Food Addit Contam A. 26:1433-1449.

De Neve M, Sioen I, Boon PE, Arganini C, Moschandreas J, Ruprich J, Lafay L, Amiano P, Arcella D, Azpiri M, et al. 2010. Harmonisation of food categorisation systems for dietary exposure assessments among European children. Food Addit Contam A. 27:1639-1651.

Enghardt-Barbieri H, Pearson M, Becker W. 2006. Riksmaten. 2003. Livsmedels - och näringsintag bland barn i Sverige (with a summary in English). Uppsala (Sweden): Livsmedelsverket (National Food Administration).

European Commission. 2002. Regulation (EC) No. 178/2002 of the European Parliament and of the Council of 28 January 2002 laying down the general principles and requirements of food law, establishing the European Food Safety Authority and laying down procedures in matters of food safety. Off J Eur Commun. L 31:1-24.

European Commission. 2006. Commission Regulation (EC) No. 1881/2006 of 19 December 2006 setting maximum levels of certain contaminants in foodstuffs. Off $\mathrm{J}$ Eur Commun. L 364:5-24.

European Food Safety Authority (EFSA). 2009. General principles for the collection of national food consumption data in the view of a pan-European dietary survey. EFSA J. 7(12):1435. Available from: http://www.efsa.europa.eu/

European Food Safety Authority (EFSA). 2010a. Revised exposure assessment for lycopene as a food colour on request from the European Commission. EFSA J. 8(1):1444. Available from: http://www.efsa.europa.eu/

European Food Safety Authority (EFSA). 2010b. Scientific Opinion on lead in food. EFSA Panel on Contaminants in the Food Chain (CONTAM). EFSA J. 8(4):1570. Available from: http://www.efsa.europa.eu/

European Food Safety Authority (EFSA). 2010c. Scientific Opinion on melamine in food and feed. EFSA Panel on Contaminants in the Food Chain (CONTAM) and EFSA Panel on Food Contact Materials, Enzymes, Flavourings and Processing Aids (CEF). EFSA J. 8(4):1573. Available from: http://www.efsa.europa.eu/

European Food Safety Authority (EFSA). 2011a. Evaluation of the FoodEx, the food classification system applied to the development of the EFSA Comprehensive European Food Consumption Database. EFSA J. 9(3):1970. Available from: http://www.efsa.europa.eu/

European Food Safety Authority (EFSA). 2011b. Overview of the procedures currently used at EFSA for the assessment of dietary exposure to different chemical substances. EFSA J. 9(12):2490. Available from: http://www.efsa. europa.eu/

European Food Safety Authority (EFSA). 2011c. Use of the EFSA Comprehensive European Food Consumption Database in Exposure Assessment. EFSA J. 9(3):2097. Available from: http://www.efsa.europa.eu/

European Food Safety Authority (EFSA). 2012. Cadmium dietary exposure in the European population. EFSA J. 10(1):2551. Available from: http://www.efsa. europa.eu/

Hoffmann K, Boeing H, Dufour A, Volatier JL, Telman J, Virtanen M, Becker W, De Henauw S. 2002. Estimating the distribution of usual dietary intake by short-term measurements. Eur J Clin Nutr. 56(Suppl. 2):S53-S62.

Huybrechts I, Matthys C, Pynaert I, De Maeyer M, Bellemans M, De Geeter H, De Henauw S. 2008. Flanders preschool dietary survey: rationale, aims, design, methodology, and population characteristics. Arch Public Hlth. 66:5-25.

Huybrechts I, Sioen I, Boon PE, De Neve M, Amiano P, Arganini C, Bower E, Busk L, Christensen T, Hilbig A, et al. 2010. Long-term dietary exposure to food colours in young children living in different European countries. Scientific Report submitted to EFSA. Available from: http://www.efsa.europa.eu/

Huybrechts I, Sioen I, Boon PE, Ruprich J, Lafay L, Turrini A, Amiano P, Hirvonen T, De Neve M, Arcella D, et al. 2011. Dietary exposure assessments for children in Europe (the EXPOCHI project): rationale, methods and design. Arch Public Hlth. 69:4. Available from: http:/ www.archpublichealth.com/content/pdf/0778-7367-69-4.pdf

Kroke A, Manz F, Kersting M, Remer T, Sichert-Hellert W, Alexy U, Lentze MJ. 2004. The DONALD Study. History, current status and future perspectives. Eur J Clin Nutr. 43:45-54.

Larrañaga LN, Amiano EP, Gorostiza GE, Pérez DY, Bidaurrazaga-van Dierdonck J, Sarasqueta EC, Arrizabalaga AJJ, Espada SM, Méndez NI. 2006. Encuesta de nutrición 2005: Hábitos alimentarios y estado de salud de la población vasca de 4 a 18 años. Primeros resultados. Vitoria-Gasteiz: Servicio Central de Publicaciones del Gobierno Vasco, DL. Available 
from: http://www.osakidetza.euskadi.net/r85-publ01/es/ contenidos/informacion/publicaciones_informes_estudio/ es_pub/adjuntos/EncuestaNutricion2005.pdf

Leclercq C, Arcella D, Piccinelli R, Sette S, Le Donne C, Turrini A, INRAN-SCAI 2005-06 Study Group. 2009. The Italian National Food Consumption Survey INRAN-SCAI 2005-06: main results in terms of food consumption. Publ Hlth Nutr. 12:2504-2532.

Linardakis M, Sarri K, Pateraki M, Sbokos M, Kafatos A. 2008. Sugar-added beverages consumption among kindergarten children of Crete: effects on nutritional status and risk of obesity. BMC Publ Hlth. 8:279. Available from: http:// www.biomedcentral.com/content/pdf/1471-2458-8-279.pdf

Lyhne N, Christensen T, Groth MV, Fagt S, Biltoft-Jensen A, Hartkopp H, Hinsch H-J, Matthiessen J, Møller A, Saxholt E, et al. 2005. Dietary habits in Denmark 2000 2002, main results. Copenhagen (Denmark): Danish Institute for Food and Veterinary Research, Department of Nutrition.

Ocké MC, van Rossum CTM, Fransen HP, Buurma EJM, de Boer EJ, Brants HAM, Niekerk EM, van der Laan JD, Drijvers JJMM, Ghameshlou Z. 2008. Dutch National Food Consumption Survey - Young children 2005/2006. RIVM Report 350070001. Bilthoven (the Netherlands): National Institute for Public Health and the Environment (RIVM). Available from: http://www.rivm.nl/

Räsänen M, Kronberg-Kippilä C, Ahonen S, Uusitalo L, Kautiainen S, Erkkola M, Veijola R, Knip M, Kaila M, Virtanen SM. 2006. Intake of vitamin D by Finnish children aged 3 months to 3 years in relation to sociodemographic factors. Eur J Clin Nutr. 60:1317-1322.

Ruprich J, Dofkova M, Rehurkova I, Slamnenikova E, Resova D. 2006. Individual food consumption - the national study SISP04. Prague (Czech Republic): CHFCH NIPH. Available from: http://czvp.szu.cz/ spotrebapotravin.htm/

Serra-Majem L, García-Closas R, Ribas L, Pérez-Rodrigo C, Aranceta J. 2001. Food patterns of Spanish schoolchildren and adolescents: the enKid Study. Publ Hlth Nutr. 4:1433-1438.

Simell O, Niinikoski H, Rönnemaa T, Raitakari OT, Lagström H, Laurinen M, Aromaa M, Hakala P, Jula A, Jokinen E, et al. 2009. Cohort profile: The STRIP Study (Special Turku Coronary Risk Factor Intervention Project), an infancy-onset dietary and life-style intervention trial. Int $\mathrm{J}$ Epidemiol. 38:650-655.

Sioen I, Boon PE, Huybrechts I, De Neve M, Amiano P, Arganini C, Busk L, Chadjigeorgiou C, Christensen T, Hilbig A, et al. 2010. Long-term dietary exposure to selenium in young children living in different European countries. Scientific Report submitted to EFSA. Available from: http://www.efsa.europa.eu/

Van Dooren MMH, Boeijen I, van Klaveren JD, van Donkersgoed G. 1995. Conversie van consumeerbare voedingsmiddelen naar primaire agrarische produkten (Conversion of consumed foods into raw agricultural commodities). RIKILT Report 95.17. Wageningen (the Netherlands): RIKILT Institute for Food Safety, Wageningen University and Research centre. Available from: www.rikilt.wur.nl/

Vreman K, van der Veen NG, van der Molen EJ, de Ruig WG. 1986. Transfer of cadmium, lead, mercury, and arsenic from feed into milk and various tissues of dairy cows - chemical and pathological data. Neth J Agric Sci. 34:129-144.

\section{Appendix 1}

Table A1. Mean lead concentration per food group ${ }^{\mathrm{a}, \mathrm{b}}$ as used in the EXPOCHI project following two scenarios of assigning lead concentrations to non-detect samples.

\begin{tabular}{lcc}
\hline & Mean lead concentration $\left(\mu \mathrm{gg}^{-1}\right)^{\mathrm{c}}$ \\
\cline { 2 - 3 } Food group & $\mathrm{LB}$ & $\mathrm{UB}$ \\
\hline Composed foods - cereal-based mixed dishes and cereal-based desserts & 28 \\
Vegetables excluding dried vegetables & 4.5 & 46 \\
Nuts/seeds & 33 & 63 \\
Coffee/tea in concentrated and in powdered form & 3.8 & 6.1 \\
Chocolate (products) & 31 & 41 \\
Fruit excluding dried fruit & 11 & 23 \\
Dried fruit & 35 & 45 \\
Fresh and dried herbs, spices, seasonings and condiments & 213 & 225 \\
Food supplements & 711 & 727 \\
Waters & 1.5 & 3.0 \\
Sugar, sweeteners and sugar products (e.g. sugar-based confectionery, & 27 & 55 \\
chewing gum and decorations) & & 55 \\
Fats, oils and fat emulsions (also, for example, rice milk (no soy milk)) & 29 & 47 \\
Composed foods: meat-based mixed dishes & 16 & 43 \\
Composed foods: fish-based mixed dishes & 22 & 385 \\
Dried vegetables & 380 & 7.5 \\
Pulses/legumes & 16 & 12 \\
Soy milk/soy-based dessert & 4.0 & 44 \\
Milk/dairy drinks & 5.0 & 18 \\
Cheese & & \\
\hline
\end{tabular}


Table A1. Continued.

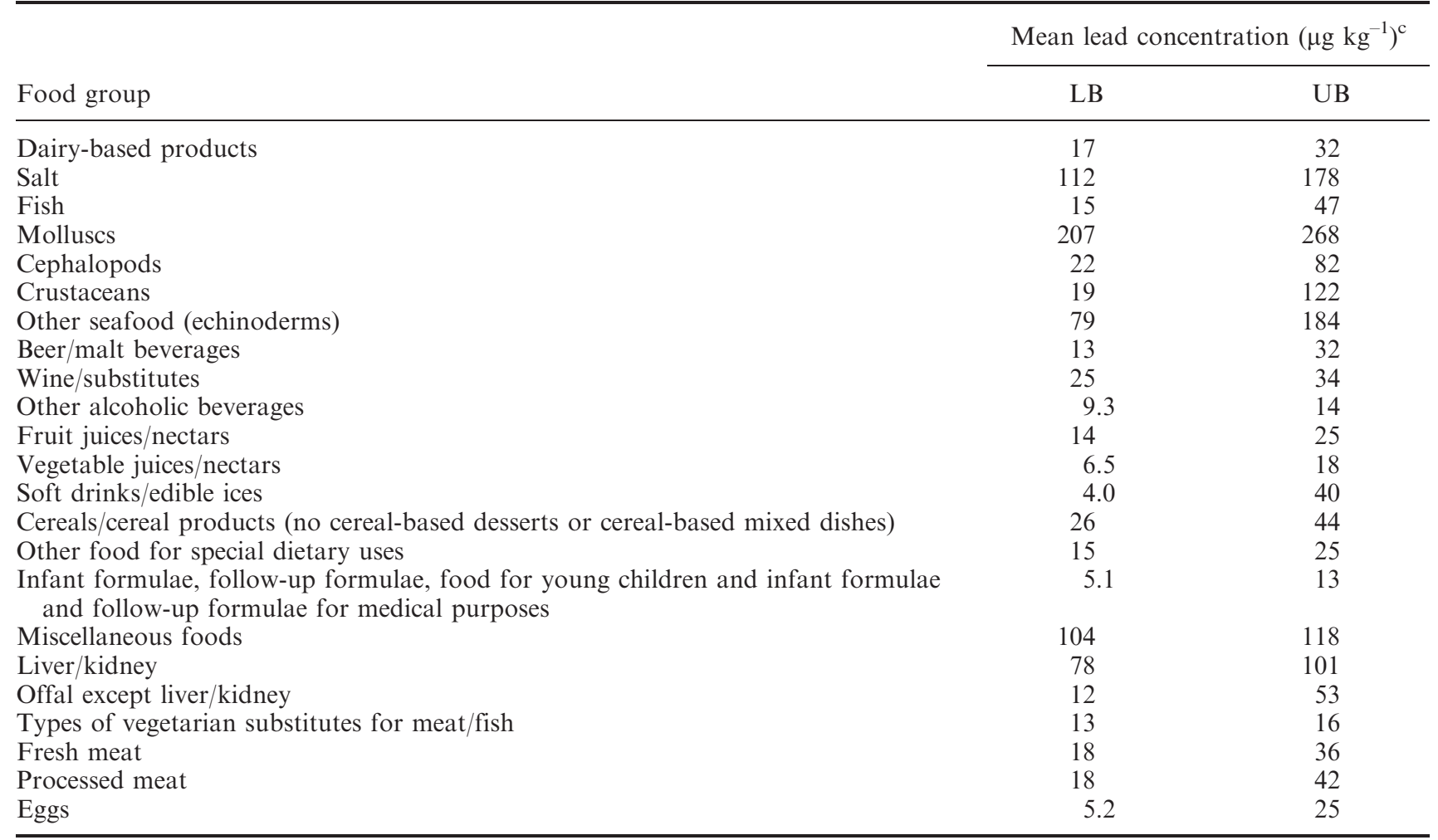

Notes: ${ }^{a}$ For a more elaborate description of (some of) the food groups, see Huybrechts et al. (2011).

${ }^{b}$ No information was available about the years in which the foods categorised in the food groups were sampled.

${ }^{\mathrm{c}}$ Samples with a lead concentration below the LOD or the LOQ were assigned either a zero concentration (LB, lower bound) or a concentration equal to the relevant limit value (UB, upper bound).

\section{Appendix 2}

Table B1. Overview of Dutch lead concentrations (2002-2008) per food ${ }^{\mathrm{a}}$ as used in national Dutch exposure calculation to lead.

\begin{tabular}{|c|c|c|c|c|c|}
\hline \multirow[b]{2}{*}{ Food } & \multicolumn{3}{|c|}{ Mean concentration $\left(\mu \mathrm{g} \mathrm{kg}^{-1}\right)$} & \multirow[b]{2}{*}{ Range $\left(\mu \mathrm{g} \mathrm{kg}^{-1}\right)^{\mathrm{e}}$} & \multirow{2}{*}{$\begin{array}{c}\text { Number of } \\
\text { samples ( } \% \text { positives })\end{array}$} \\
\hline & $\mathrm{LB}^{\mathrm{b}}$ & $\mathrm{MB}^{\mathrm{c}}$ & $\mathrm{UB}^{\mathrm{d}}$ & & \\
\hline Apple & 2.4 & 10 & 18 & $5-70$ & $51(6)$ \\
\hline Bean, green (fresh) & 4.2 & 15 & 26 & $6-40$ & $11(18)$ \\
\hline Bean, French & 1.3 & 10 & 19 & $5-9^{f}$ & $7(14)$ \\
\hline Blue berry & 17 & 17 & 17 & 17 & $1(100)$ \\
\hline Brussels sprouts & 11 & 22 & 33 & 90 & $8(13)$ \\
\hline Cabbage, oxheart/conical & 0.9 & 6.2 & 12 & $7^{\mathrm{f}}$ & $8(13)$ \\
\hline Cabbage, Savoy & 3.6 & 7.7 & 12 & $6-13$ & $8(38)$ \\
\hline Cabbage, white & 0.7 & 7.8 & 15 & 9 & $13(8)$ \\
\hline Chicken & 0.9 & 24 & 47 & $1.4-54$ & $545(7)$ \\
\hline Crab & 103 & 137 & 170 & $290-330$ & $6(33)$ \\
\hline Currant (red, white, black) & 22 & 22 & 22 & 22 & $1(100)$ \\
\hline Date & 40 & 40 & 40 & 40 & $1(100)$ \\
\hline Eel & 2.1 & 28 & 53 & $11-110$ & $85(4)$ \\
\hline $\mathrm{Egg}^{\mathrm{g}}$ & 5.2 & 25.2 & 25.2 & - & - \\
\hline
\end{tabular}


Table B1. Continued.

Mean concentration $\left(\mu \mathrm{g} \mathrm{kg}^{-1}\right)$

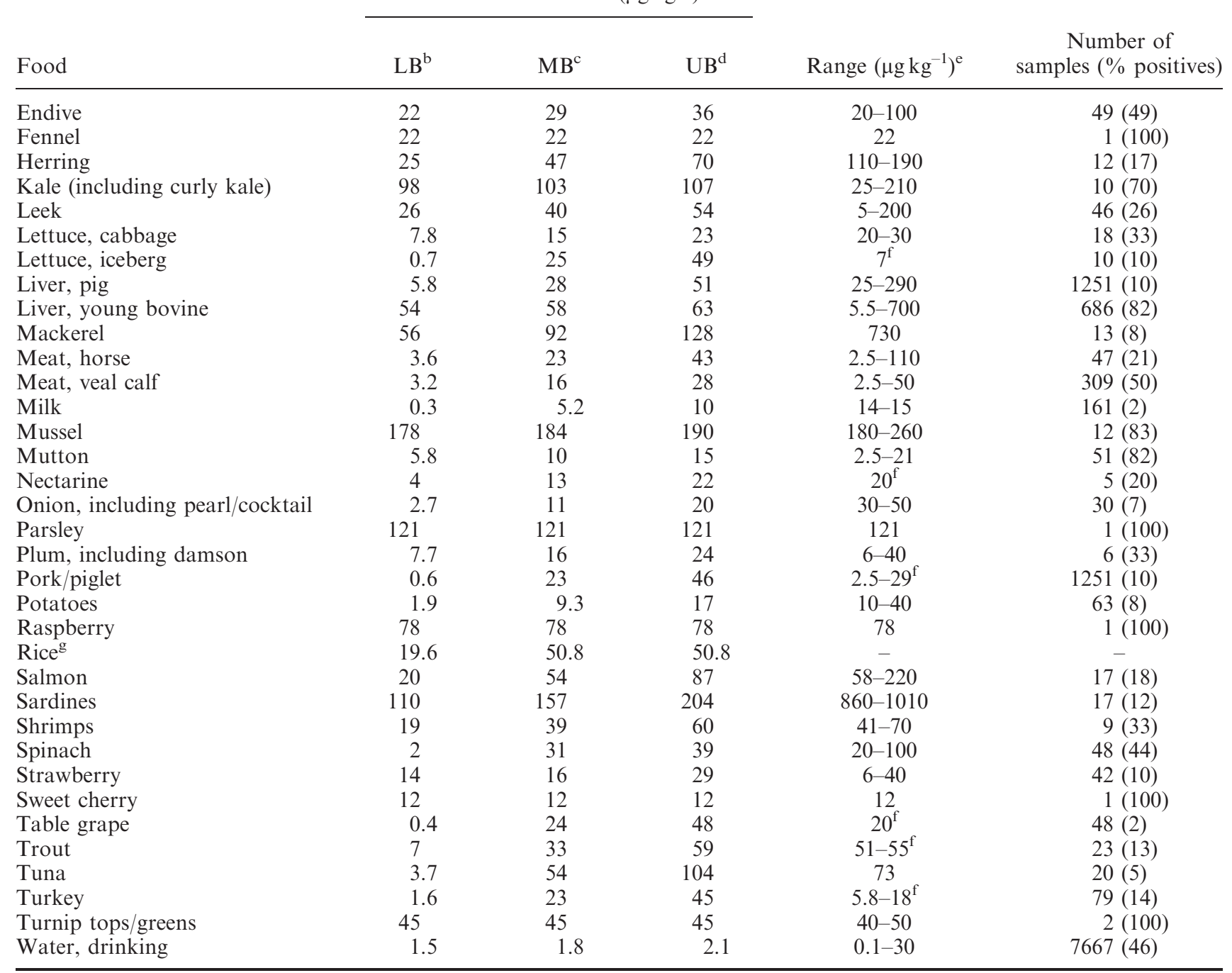

Notes: ${ }^{\mathrm{a}}$ The foods listed contain those foods with at least one sample analysed with a lead concentration at or above the LOD or the LOQ. The foods analysed without detectable/quantifiable concentrations of lead included - with, in parentheses, the number of samples analysed and the concentration $\left(\mu \mathrm{g} \mathrm{kg}^{-1}\right)$ assigned in the UB concentration scenario, respectively - anchovy (9; 100), apricot $(1 ; 30)$, asparagus $(3 ; 8)$, avocado $(1 ; 10)$, banana $(1 ; 18)$, blackberry $(1 ; 10)$, bleach celery $(3 ; 20)$, broad bean $(2 ; 30)$, broccoli $(6 ; 22)$, brown bean (dry harvested) $(1 ; 30)$, cauliflower $(12 ; 12)$, chicory $(1 ; 10)$, Chinese cabbage $(5 ; 72)$, coconut $(2 ; 300)$, cod $(7 ; 55)$, courgette $(3 ; 23)$, cucumber $(31 ; 20)$, egg plant $(3 ; 23)$, green/(garden)peas (fresh) $(5 ; 30)$, honey $(6 ; 50)$, infant food $(38 ; 78)$, kiwi $(1 ; 30)$, lambs lettuce $(1 ; 30)$, legume (fresh) $(4 ; 12)$, lentils (dry harvested) $(1 ; 30)$, mango $(2 ; 155)$, melon $(3 ; 27)$, olive $(3 ; 15)$, orange $(5 ; 18)$, papaya $(2 ; 10)$, pear $(13 ; 14)$, peach $(5 ; 20)$, pineapple $(1 ; 10)$, plaice $(6 ; 56)$, pollack $(2 ; 68)$, radish $(5 ; 26)$, red cabbage $(20 ; 20)$, rhubarb $(1 ; 30)$, sole $(7 ; 56)$, string bean $(1 ; 10)$, sweet corn $(1 ; 30)$, sweet pepper $(11 ; 14)$, and tomato $(16 ; 21)$.

${ }^{\mathrm{b}} \mathrm{LB}=$ lower bound; non-detect samples were assigned $0 \mu \mathrm{g} \mathrm{kg}^{-1}$.

${ }^{\mathrm{c}} \mathrm{MB}=$ medium bound; non-detect samples of foods (except drinking water) with at least one sample with a concentration at or above the LOD or the LOQ were assigned a concentration equal to 0.5 LOD or 0.5 LOQ. The remaining non-detect samples were assigned $0 \mu \mathrm{g} \mathrm{kg}^{-1}$.

${ }^{\mathrm{d}} \mathrm{UB}=$ upper bound; non-detect samples were assigned a concentration equal to the LOD or the LOQ.

${ }^{\mathrm{e}}$ Range of concentrations analysed above the LOD or the LOQ.

${ }^{\mathrm{f}} \mathrm{The}$ range of analysed concentrations does not include the UB concentration (and for some commodities also not the MB concentration) due to a reported LOD/LOQ that exceeded the analysed concentrations.

${ }^{\mathrm{g}}$ For cereals, eggs and rice the listed concentrations were obtained from European Food Safety Authority (EFSA) (2010b). The mean MB concentration refers to the UB concentrations as used by EFSA (2010b) to assess the UB exposure to lead. No MB concentrations were reported.

${ }^{\mathrm{h}}$ Cereals include wheat, rye, maize, millet, oat, buckwheat and barley. 